\title{
EFEKTIVITAS KONSELING KELOIMPOK BERBANTUAN TEKNIK PROBLEI
SOLVING UNTUK MENURUNKAN PERILAKU MEMBOLOS PESERTA DIDIK
}

\section{Effectiveness Of Helpful Groups Of Problem Solving Techniques To Reduce Behavior Of Breaking Students}

\author{
'Elza, ${ }^{2}$ Dina Fariza TS \\ IUniversitas Muhammadiyah Palangkaraya, Jekan Raya, Palangka Raya, Kalimantan Tengah, Indonesia \\ 2 Universitas Muhammadiyah Palangkaraya, Jekan Raya, Palangka Raya, Kalimantan Tengah, Indonesia
}

\section{ARTIKEL INFO}

Diterima

Juni 2017

Dipublikasi

Agustus 2017

*E-mail:

dinafarizats@gmail.com

Orchid:
Tujuan penelitian ini untuk Mengetahui tingkat perilaku membolos pada peserta didik dan mengetahui kefektifitasan layanan konseling kelompok berbantuan metode problem solving untuk menurun kanperilaku membolos pada peserta didik. Metodologi penelitianyang dipakai yaitu experiment. Populasi dalam penelitian ini yaitu peserta didik SMA negeri 2 plangkaraya dengan sampel kelsa X SMA negeri 2 palangkaraya. Hasil penelitian menunjukan bahwa konsleing kelompok dengan teknik problem solving efektik untuk mengurangi perilaku membolos peserta didik, dibuktikand dengan skor pretest dan postes skala yang sudah di bagikan kepada 8 peserta didik LA (I48) berkurang mnejadi 60, EDL (I25) berkurang menjadi 55, AWN (I2I) berkurang menjadi73. RFBB (I54) berkurang menjadi 98, AYS (I52) berkurang menjadi I3I, pns (II4) berkurang menjadi 57, gesp (I32) berkurang menjadi 55 dan ET (127) berkurang menjadi 72 terjadi penurunan rata-rata hasil pretest dan post-test. Penurunan rata-rata awal 191.50 menjadi 69.00 , dengan jumlah rata-rata penurunan sebesar 65.I3. Maka dari itu konseling kelompok dengan teknik problem solving baik untuk diterapkan pada dunia pendidikan sebagai salah satu bentuk pelayanan bimbingan dan konseling disekolah.

Kata kunci: konseling kelompok, teknik problem solving, perilaku membolos

\section{ABSTRACT}

The purpose of this study was to determine the level of truant behavior in students and find out the effectiveness of group counseling services assisted by problem solving methods to decrease truant behavior in students. The research methodology used is the experiment. The population in this study were 2 plangkaraya public high school students with sample $X$ SMA Negeri 2 palangkaraya. The results showed that group counseling with effective problem solving techniques to reduce students' truant behavior was evidenced by the scale pretest and posttest scores that had been distributed to 8 LA students (I48) reduced to 60 , EDL (I25) reduced to 55 , AWN (I2I) reduced to 73. RFBB (I54) reduced to 98 , AYS (I52) reduced to 131 , pns (II 4 ) reduced to 57 , gesp (I32) reduced to 55 and ET (I27) reduced to 72 resulting in a decrease in the average pre-test and post- results test. The decrease in the initial average was 191.50 to 69.00, with an average decrease of 65.13. So from that group counseling with good problem solving techniques to be applied to the world of education as one form of guidance and counseling services at school.

Keywords: group counseling, problem solving techniques, truant behavior 
Jurnal Bimbingan dan Konseling

\section{PENDAHULUAN}

Bimbingan dan konseling adalah pelayanan bantuan untuk peserta didik, baik seacara perorangan maupun kelompok agar mandiri dan bisa berkembang secara optimal, dalam bidang bimbingan pribadi, sosial, belajar, dan karier melalui berbagai jenis layanan dan kegiatan pendukung berdasarkan norma-norma yang berlaku. Pelayanan bimbingan dan konseling yang sedang dikembangkan di Indonesi ini adalah bimbingan dan konseling yang berorientasi pada perkembangan, yaitu pelayanan bimbingan dan konseling yang lebih mengutamakan dan mengedepankan berbagai bentuk dan jenis layanan yang memungkinkan peserta didik dapat mengurangi perilaku yang dapat menjadi permasalahan peserta didik di sekolah dan terkembangnya segenap potensi yang dimiliki peserta didik. Yang membantu peserta didik dalam menangani masalahnya di sekolah yaitu konselor dan guru-guru yang ada disekolah, di dalam lingkungan sekolah guru bisa berkolaborasi dengan profesi pendidik lain, selain guru yaitu konselor dan pengembang kurikulum.

Adapun tugas-tugas konselor disekolah adalah untuk membantu peserta didik dalam bidang pribadi, sosial, akademik dan karier. Dalam bidang pribadi yang dimana permasalahan peserta didik mengenai tentang permasalahan pribadi dalam pergaulan, keluarga dan hubungan pribadi lawan jenis. Dalam bidang akademik permasalahan peserta didik mengahadapi pelajaran disekolah, motivasi belajar dan tingkat akademik disekolah. Dalam bidang sosial peserta didik dengan pergaulan, hubungan antara guru dan peserta didik dan cara bersosialisasi peserta didik. Dalam bidang karier peserta didik dengan masa depannya dalam mengambil jurusan, pemilihan pekerjaan serta pemilihan jurusan peserta didik setelah lulus sekolah.

Salah satu bidang garapan pada bimbingan dan konseling disekolah adalah bidang pribadi peserta didik mengenai permasalahan peserta didik yang membolos pada saat jam pelajaran, ada nya perkelahian antar teman, membully sesama teman disekolah, melanggar tata tertib yang ada disekolah.

Berdasarkan hasil observasi dan wawancara dengan guru BK di sekolah SMA 2 Palangka Raya pada hari selasa tanggal 21 Desember 20I5, peneliti mendapati fenomena yang peserta didiknya ketahuan membolos pada saat jam pelajaran berlangsung dengan berbagai alasan yang di ucapkan peserta didik seperti hal nya dengan alasan izin pulang mengambil tugas yang ketinggalan di rumah dan pada akhirnya peserta didik tidak kembali ke sekolah, izin berpura-pura sakit ke Usaha Kesehatan Sekolah (UKS) yang ternyata di Usaha Kesehatan Sekolah (UKS) peserta hanya ingin bersantai untuk tidur-tiduran dan tidak sakit, peserta didik yang keluar sekolah tanpa meminta surat ijin dari sekolah, peserta didik yang memiliki perilaku membolos dapat mempengaruhi teman-temannya, sampai membolos untuk merokok di luar sekolah.

Permasalahan yang terjadi pada peserta didik yaitu perilaku membolos dengan bermacam-macam alasan dari peserta didik untuk membela diri mereka agar tidak mendapatkan hukuman yang berat atau dapat surat panggilan orang tua serta surat pelanggaran tata tertib, perilaku membolos juga termasuk dalam kenakalan remaja yang terjadi di sekolah dan dapat berakibat buruk pada peserta didik itu sendiri bahkan akan berakibat buruk juga kepada teman, keluarga dan lingkungan sosialnya. Menurut Kartono (20I4: 2I), menyatakan bahwa: "Membolos sekolah lalu bergelandangan sepanjang jalan atau bersembunyi di tempat-tempat terpencil sambil melakukan eksperimen bermacammacam kedurjanaan dan tindak a-susila."

M. Andi Setiawan (2016: 24) Membolos sebagai perilaku yang tidak tepat karena individu kurang bisa dalam memuaskan 
Jurnal Bimbingan dan Konseling

kebutuhanya, akibatnya kehilangan sentuhan dengan realita objektif, seseorang tidak dapat melihat sesuatu sesuai dengan realitanya, tidak dapat melakukan atas dasar kebenaran, tanggung jawab dan realita

Tidak hanya menggunakan layanan konseling kelompok saja peneliti juga menggunakan teknik problem solving dalam membantu peserta didik yang teridentifikasi membolos atau pernah membolos dapat mengurangi perilaku membolos dan peserta didik mampu memahami pada saat pelaksanaan teknik problem solving. M. Andi Setiawan (2015: 9) Konseling kognitif behavior memiliki beraneka ragam teknik yang dapat digunakan. Salah satu teknik yang dipandang efektif adalah teknik problem solving. Menurut Majid (2012:I42) menyatakan bahwa "Metode pemecahan masalah (Problem Solving) merupakan cara memberikan pengertian dengan menstimulasi anak didik untuk memperhatikan, menelaah dan berpikir tentang suatu masalah untuk selanjutnya menganalisis masalah tersebut sebagai upaya memecahkan masalah.”

Problem solving menurut Nezu, A.M., Nezu, C.M., \& Lombardo, E (2004: 9) dalam M. Andi Setiawan (2015: 34) yaitu: (I) mendefinisikan masalah, (2) menghasilkan alternatif, (3) membuat keputusan, dan (4) mengevaluasi solusi. M. Andi Setiawan (2015: 34) Konseling kelompok teknik problem solving adalah strategi perilaku kognitif yang mengajarkan orang cara untuk menangani masalah dalam kehidupan sehari-hari mereka. Tujuan utamanya adalah untuk mengidentifikasi solusi yang paling efektif untuk masalah yang dihadapi dan untuk memberikan pelatihan sistematis keterampilan kognitif.

Dari hasil wawancara dengan guru Bimbingan dan Konseling (BK) di sekolah peneliti mendapatkan hasil yaitu ada 8 peserta didik yang kedapatan membolos pada saat jam pelajaran, dan hasil observasi pada saat peserta didik yang kedapatan membolos berada di ruangan Bimbingan dan Konseling (BK) sedang mengisi surat pelanggaran tata tertib karena membolos pada saat jam pelajaran. Dari surat pelanggaran tata tertib tersebut data skunder berupa surat pelanggaran tata tertib yang di dapat dari guru BK, bahwa peserta didik yang melanggar tata tertib yaitu membolos pada jam pelajaran data ini yang membuktikan bahwa peserta didik yang di teliti benar-benar melakukan perilaku membolos

\section{METODOLOGI PENELITIAN}

Penelitian ini menggunkan pendekatan eksperimen. Menurut Sanjaya (2013) "Eksperimen adalah metode penelitian yang bertujuan untuk menjelaskan dan meramalkan yang akan terjadi pada suatu variabel manakala diberikan suatu perlakuan tertentu pada variabel lainnya". Menurut Arikunto (2013: 3) "adalah suatu cara untuk mencari sebab akibat (hubungan kausal) antara dua faktor yang sengaja ditimbulkan oleh peneliti dengan mengurangi atau menyisihkan faktor-faktor lain yang bisa mengganggu".

Berdasarkan pendapat di atas dapat disimpulkan bahwa eksperimen adalah metode penelitian yang mencari besarnya pengaruh dan meramalkan yang akan terjadi pada suatu variabel manakala diberikan suatu perlakuan tertentu pada variabel lainnya.

\section{HASIL DAN PEMBAHASAN}

Berikut ini sajian perbandingan hasil pengukuran tingkat perilaku membolos dengan menggunakan skala perilaku membolos saat pre-testdan post-test pada subjek penelitian. Data hasil pre-test dan posttest pada subjek dilengkapi dengan deskripsi perubahan dan perubahan pada diri peserta didik masing-masing peserta didik pada subjek dan berikut adalah hasil pre-test dan post-test subjek penelitian. 


\section{Table I}

Hasil pre-test dan post-test pada subjek penelitian

\begin{tabular}{|c|c|c|c|c|}
\hline $\begin{array}{c}\text { Peserta } \\
\text { didik }\end{array}$ & $\begin{array}{c}\text { Skor pre- } \\
\text { test }\end{array}$ & Kategori & $\begin{array}{c}\text { Skor post- } \\
\text { test }\end{array}$ & Kategori \\
\hline LA & 148 & Tinggi & 60 & Sangat rendah \\
\hline EDL & 125 & Sedang & 55 & Sangat Rendah \\
\hline AWN & 121 & Sedang & 73 & Rendah \\
\hline RFBB & 154 & Tinggi & 98 & Sedang \\
\hline AYS & 152 & Tinggi & 131 & Tinggi \\
\hline PNS & 114 & Sedang & 57 & Sangat rendah \\
\hline GESAP & 132 & Tinggi & 55 & Sangat rendah \\
\hline ET & 127 & Sedang & 72 & rendah \\
\hline
\end{tabular}

\section{KESIMPULAN}

Berdasarkan hasil penelitian yang dilakukan oleh peneliti, maka dapat diambil simpulan bahwa adanya penurunan perilaku membolos pada peserta didik dilihat dari sebelum diberikan intervensi dan sesudah intervensi. Layanan konseling kelompok dengan teknik problem solving dapat dikatakan Menurunkan Perilaku Membolos Pada Peserta Didik Kelas XI IPA di SMA 2 Palangka Raya Tahun Ajaran 2016/2017. Karena terjadi penurunan rata-rata hasil pre-test dan post-test. Penurunan rata-rata awal 191.50 menjadi 69.00 , dengan jumlah rata-rata penurunan sebesar 65.13. Maka dari itu konseling kelompok dengan teknik problem solving baik untuk diterapkan pada dunia pendidikan sebagai salah satu bentuk pelayanan bimbingan dan konseling disekolah

\section{DAFTAR PUSTAKA}

Arikunto, S. 2013. Prosedur Penelitian: Suatu Pendekatan Praktik. Jakarta: Rineka Cipta.

Kartono, Kartini. 20I4. Kenakalan Remaja. Jakarta: PT Raja Grafindo. Persada

M. Andi Setiawan. 2016. Efektivitas Konseling Kelompok Teknik Problem Solving Untuk Meningkatkan Efikasi Diri Akademik Siswa. Suluh Jurnal Bimbingan dan Konseling, Agustus 2015, Volume I Nomor I, (33 - 36) ISSN: 2460-727
M. Andi Setiawan. 2015. Efektivitas Konseling Kelompok Teknik Problem Solving Untuk Meningkatkan Efikasi Diri Akademik Siswa. Suluh Jurnal Bimbingan dan Konseling, Agustus 2015, Volume I Nomor I, $(33$ - 36) ISSN: 2460-727.

M. Andi Setiawan. 20I5. Model Konseling Kelompok Dengan Teknik Problem Solving Untuk Meningkatkan SelfEfficacy Akademik Siswa. Jurnal Bimbingan Konseling 4 (I) (20I5) ISSN 2252-6889.

Majid, Abdul. 2012. Perencanaan Pembelajaran. Bandung: Rosda Karya

Sanjaya, Wina. 2013. Penelitian Pendidikan, Jenis, Metode dan Prosedur. Jakarta: Kencana Prenada Media Group 